\title{
Democracia, participação e inclusão política: um estudo sobre as conferências de políticas para as mulheres de Belo Horizonte*
}

\author{
Flávia de Paula Duque Brasil \\ Fundação João Pinheiro (FJP)
}

Girlene Galgani Reis

Fundação João Pinheiro (FJP)

\begin{abstract}
A participação da sociedade nas decisões relativas às políticas públicas tem-se ampliado no contexto brasileiro com a criação de instituições participativas sob vários desenhos institucionais. Partindo da perspectiva de aprofundamento democrático no campo da democracia participativa e deliberativa, o artigo teórico-empírico aborda as instituições participativas e seu potencial de inclusão política, caracterizando especificamente as conferências de políticas públicas. Em um estudo de caso, analisam-se as conferências de políticas para as mulheres realizadas em Belo Horizonte de 2004 a 2010, sob o enfoque da inclusão política e da incorporação das deliberações coletivas como orientadoras de políticas públicas. O trabalho baseia-se em pesquisa qualitativa desenvolvida em 2012, empregando levantamentos documentais e entrevistas semiestruturadas com as conselheiras do Conselho Municipal de Direitos da Mulher, instância corresponsável pelas conferências. Na perspectiva das conselheiras, as conferências têm favorecido a inclusão política, embora considerem que suas resoluções não têm afetado de forma sistemática as políticas públicas.
\end{abstract}

Palavras-chave: participação social, políticas públicas, gênero, democracia, administração regional, estudo de caso

\footnotetext{
*Uma versão preliminar deste artigo foi apresentada no XXXVII Encontro da Anpad - EnAnpad 2013. Os autores agradecem ao apoio da Fapemig.
}

Artigo recebido em dezembro de 2013. Versão final em novembro de 2014. 
Democracia, participación e inclusión política: un estudio sobre las conferencias de políticas para las mujeres de Belo Horizonte

La participación societaria en las decisiones relativas a las políticas públicas viene ampliándose en el contexto brasileño con la creación de instituciones participativas bajo varios diseños institucionales. Tomando como punto de partida la perspectiva de profundización democrática en el campo de la democracia participativa y deliberativa, este artículo teórico-empírico trata de las instituciones participativas y su potencial de inclusión política, caracterizando específicamente las Conferencias de Políticas Públicas. En un estudio de caso, se focalizaron las Conferencias de Políticas Públicas para las Mujeres realizadas en Belo Horizonte, de 2004 a 2010, analizadas bajo el enfoque de la inclusión política y de la incorporación de las deliberaciones colectivas como orientadoras de las políticas públicas. El estudio utiliza una investigación cualitativa desarrollada en 2012 y emplea levantamientos documentales y entrevistas semiestructuradas con las Consejeras del Consejo Municipal de Derechos de la Mujer, instancia corresponsable por las Conferencias. Desde la perspectiva de las consejeras, las conferencias vienen favoreciendo la inclusión política, aunque consideran que sus resoluciones no afectan de forma sistemática las políticas públicas.

Palabras-clave: participación social, políticas públicas, gênero, democracia, administración regional, estudio de caso

\section{Democracy, participation and inclusion policy: a study of the Conference of Policy for Women in the city of Belo Horizonte (Brazil)}

Society's participation in decisions related to public policies has been expanded in the Brazilian context by the creation of participatory institutions under different designs. Starting from the perspective of democratic deepening in the field of participatory and deliberative democracy, this theoretical and empirical article discusses participatory institutions and their potential for political inclusion, specifically characterizing the Conferences of Public Policy. In a case study, we focus on the Conference on Policies for Women held in the city of Belo Horizonte (Brazil) from 2004 to 2010, approaching political inclusion and the incorporation of collective deliberations as guides of public policy. The article is based on a qualitative research conducted in 2012, employing a documentary survey and semistructured interviews with the councilors of the Municipal Council of Women's Rights, a body co-responsible for the Conferences. On the Councilors' perspective, the Conferences have favored political inclusion, although they consider that the resolutions have not systematically affected the public policies.

Keywords: social participation, public policy, gender, democracy, local administration, case study 


\section{Introdução}

A concepção de democracia tem sido historicamente objeto de disputa teórica, notadamente nas últimas décadas do século anterior. Alargaram-se os debates em torno da qualidade da democracia e ampliação das práticas de participação, que favorecem a inclusão política de segmentos mais amplos da sociedade. As concepções de democracia participativa e deliberativa, tendo como um dos parâmetros a noção de soberania popular, configuram-se em um campo fundado nos compromissos de aprofundamento democrático, seja mediante a organização da sociedade civil e sua influência no âmbito institucional, seja da incidência societária nos processos de decisão.

Destaca-se, no Brasil, notadamente a partir da Constituição Federal de 1988, o surgimento de diversos fóruns de participação e deliberação que redirecionam os processos decisórios, propiciando o fortalecimento da democracia participativa e delineando um vasto campo de estudos. Multiplicam-se experiências inovadoras de participação que reconfiguram o planejamento e a gestão das políticas públicas, constituindo inúmeras instituições participativas (IP) com variedade de desenhos institucionais que expressam novas relações entre sociedade e governo, entre elas, as conferências de políticas públicas (CPP) e seus desdobramentos.

A partir dessa nova configuração democrática, diversos processos decisórios públicos ocorrem em sintonia com a sociedade civil nessas instituições participativas. Entretanto, percebe-se que os novos formatos participativos precisam avançar e incidir diretamente nas questões que envolvem os interesses coletivos. Nesse sentido, Moroni (2009) afirma que o principal objetivo estratégico da democracia participativa é a universalização da cidadania, sob o ponto de vista ético e político, que, ao ser estendida às pessoas, permite a cobertura de direitos iguais e a responsabilidade de efetivá-los. De forma complementar, Faria (2000) aponta que a política deliberativa é definida por duas vias: a formação da vontade democraticamente constituída em espaços institucionais e a construção da opinião informal em espaços extrainstitucionais. É no encontro dessas duas vias que se legitima um governo democrático na concepção deliberativa. Portanto, a democracia deliberativa deve ser analisada mediante a conexão entre esses dois polos, garantindo que as decisões políticas sejam fundamentadas e justificadas no âmbito da sociedade e as decisões referenciadas pelas políticas públicas gozem de legitimidade ao refletir a vontade coletiva por meio da participação política em fóruns públicos (FARIA, 2010).

Neste artigo destacam-se as conferências municipais de políticas para as mulheres (CMPM), que, ao se apresentarem nesses espaços de participação e deliberação propícios à inclusão política, buscam avançar na conquista de direitos e romper com as diversas condições que reproduzem a desigualdade entre gêneros. 
Fruto de pesquisa desenvolvida em 2012 e 2013, o presente trabalho teóricoempírico apresenta um estudo de caso com o foco nas três edições da CMPM realizadas em Belo Horizonte no período de 2004 a 2010. A análise volta-se para seu desenho institucional participativo e potencial inclusivo e, secundariamente, para os encaminhamentos e desdobramentos para as políticas públicas direcionadas às mulheres a partir da percepção de conselheiras que compõem o Conselho Municipal dos Direitos da Mulher.

Além da pesquisa documental realizada na Secretaria de Políticas para as Mulheres (SPM), na Prefeitura de Belo Horizonte (PBH), e no Conselho Municipal dos Direitos da Mulher (CMDM), também foram realizadas entrevistas, com perguntas abertas e fechadas, aplicadas a dez conselheiras do CMDM e direcionadas ao objeto que este estudo se propõe. A composição do CMDM é paritária, com 11 representantes governamentais e 11 da sociedade civil. As entrevistas foram realizadas com 10 conselheiras em atividade no período da pesquisa, sendo seis representantes da sociedade civil e quatro representantes da área governamental. Em função das articulações partidárias ocorridas durante o pleito municipal de 2012, algumas conselheiras governamentais solicitaram licença do conselho. Assim, o questionário foi aplicado às 10 conselheiras ativas na data da entrevista.

Destaca-se a relevância das entrevistas com as conselheiras para o enfoque pretendido, posto que as mesmas possuem importante papel de controle social, mobilização popular e articulação com o governo local, tanto na organização das conferências quanto no acompanhamento das políticas públicas. O grupo convidado a participar dessa pesquisa possui um grande conhecimento e trajetória na luta pelos direitos da mulher, sendo que todas participaram de pelo menos uma conferência. $A$ maioria das conselheiras (nove) atua, em média, há 20 anos em diversos movimentos sociais, participando de toda a trajetória de garantia de direitos na cidade. A maioria (sete) é titular do Conselho Municipal dos Direitos da Mulher (CMDM).

\section{Democracia, participação-deliberativa e potenciais de inclusão política}

A ampliação da participação societária nas decisões do Estado relativas às políticas públicas é uma demanda que vem ganhando força nas últimas décadas como um ideal a ser concretizado, principalmente em sociedades que passaram por períodos autoritários e vêm trilhando caminhos que levam a uma maior equidade social. Como antecedentes gerais, a partir dos anos 1960, a disseminação do termo "participação" ganhou destaque nos âmbito sociopolítico, sobretudo em função da efervescência das reivindicações dos novos movimentos sociais - entre os quais o movimento feminista - na busca de direitos sociais e políticos. Entre as várias reivindicações dos ativistas, a democracia participativa se apresenta como meio 
de garantir transformações políticas e ampliação das formas de participação da sociedade.

Nesse contexto, Held (1987) aponta a emergência de uma "nova esquerda", delineando concepções sobre democracia, igualdade e liberdade. O autor destaca Pateman (1970, 1985), Macpherson (1977) e Poulantzas (1980), que, embora não possuam posições idênticas, apresentam pontos de convergência e compromissos comuns. Sob essas bases, tem-se, nos termos de Held (1987), o modelo de democracia participativa, que então se colocava como o principal contramodelo à democracia legal da direita, fundada estritamente na representação eleitoral e amparada pelo modelo elitista ancorado nas ideias de Schumpeter. Nessa perspectiva, a democracia é entendida como um arranjo institucional e a participação - cuja ampliação é vista como indesejável e inviável - circunscreve-se ao voto e à escolha dos governantes.

Pateman (1970) enfatiza a participação como possibilidade de intervenção nos processos políticos de tomada de decisão, ao lado da dimensão de aprendizagem coletiva. Na concepção da autora, a sociedade participativa deve ser experimental, apta a realizar novas experiências após a reforma das estruturas rígidas impostas pelo capital privado, pelas relações de classes e outras assimetrias de poder. Por outro lado, a sociedade participativa também deve ser vista como ideal político histórico que comporia a teoria contemporânea de uma democracia moderna, e não dogmática, cuja centralidade é a participação (PATEMAN, 1970; HELD,1987).

Assim como a noção de democracia é objeto de disputa, atualmente o termo "participação" é empregado a partir de diferentes premissas e significados, que vão da representação originária do voto, vinculada ao elitismo democrático, até a perspectiva de diversas formas de participação, tanto no plano individual, como no coletivo.

A participação, inscrita no campo da democracia participativa, ocorre por meio de movimentos sociais (e outras formas de ação coletiva societária) e de instituições participativas. Fung (2004) identifica duas posições no campo da teoria participativa: uma que privilegia a participação na sociedade civil, o ativismo e a resistência política; e a outra que privilegia o Estado e suas interseções com a sociedade, apontando a transformação das instituições a partir dos processos decisórios. Para ele, a questão central da democracia participativa encontra-se na igualdade de participação direta dos cidadãos nos processos de decisão. Nessa linha, o autor destaca, ainda, a importância dos desenhos institucionais participativos.

As duas orientações podem ser identificadas também na corrente de democracia deliberativa, que compartilha, com os autores participativos, os esforços para ultrapassar a concepção elitista, prevendo novas formas de participação, de modo que ambas as correntes conformam um único campo lastreado nas premissas 
de aprofundamento democrático. A diferenciação entre ambas reside nas bases habermasianas da corrente deliberativa, que enfatizam a dimensão comunicativa e discursiva da democracia.

A partir de Habermas (1981, como citado em BRASIL, 2011), a democracia pode ser entendida como um fluxo comunicacional da "periferia" - domínios da sociedade civil - para os domínios institucionais, ou seja, a formação de vontade informal nos espaços públicos influindo no âmbito institucional.

Nesse sentido, para a teoria habermasiana, a democracia vincula-se aos processos discursivos que têm lugar nas redes públicas de comunicação, com os quais os processos de institucionalização legal e utilização administrativa do poder estão indissoluvelmente ligados (AVRITZER, 2008). As bases teóricas habermasianas não autorizaram de início a previsão da ampliação das formas de participação no âmbito institucional, circunscritas, assim, às possibilidades de influírem no âmbito institucional. Nessa perspectiva, se alinharam autores que enfatizam o papel dos movimentos sociais e outras organizações sociais, enquanto outros autores (COHEN, 2009; ChAMBers, 2009; BENHABIB, 2009; BoHMAN, 2009) buscaram avançar incorporando a previsão da participação e deliberação em ocasiões e espaços institucionalizados.

Tendo em vista concluir esta seção, cabe retomar a dupla dimensão das práticas democráticas no campo participativo, que se apresenta também no terreno deliberativo e permite ampliar o alcance e potencial de inclusividade da perspectiva deliberativa.

Avritzer (2010) é um dos autores no campo da democracia radical que consideram a complementaridade entre as formas de participação e deliberação, desde as que configuram no âmbito organizativo da sociedade civil, até as que ocorrem nos espaços das novas instituições participativas que constituem locus, por excelência, da democracia deliberativa, da possibilidade de soberania popular procedimental que conjuga participação (na dimensão decisional e deliberativa) e representação. O autor define as instituições participativas (IP) como formas diferenciadas de incorporação de cidadãos e associações da sociedade civil que possibilitam a esses atores deliberar sobre políticas públicas. Cohen e Fung (2004) também apostam em um modelo de "participação-deliberativa", envolvendo, assim, a articulação entre participação e deliberação em duas dimensões de radicalização democrática: (a) ampliação da participação-deliberativa associada à esfera pública, às associações e aos movimentos sociais; (b) criação de formas institucionalizadas de participaçãodeliberativa mediante novos arranjos institucionais voltados para incluir os cidadãos em processos decisórios (COHEN; FUNG, 2004).

Ambas as dimensões são importantes no âmbito desta pesquisa, que coloca as conferências sob foco, mas também permite destacar o papel da participação 
societária - especificamente os movimentos de mulheres e feministas - na construção de agenda e de políticas públicas voltadas para as questões tematizadas por esses atores. As colocações dos diversos teóricos indicam que a democracia é um processo em construção, principalmente nos aspectos que envolvem a inclusão política e o empoderamento do cidadão a partir da participação e das deliberações que envolvem o bem público e a justiça social. Nesse sentido, pode-se considerar que a participação social (a partir da organização e mobilização de atores coletivos e mediante a institucionalização de novos canais de participação) tem sido associada a um potencial de emancipação, radicalização democrática e mudança social. A confluência dos modelos de democracia participativa e deliberativa - mediante a conjunção de mecanismos de participação e deliberação - amplia as possibilidades de construções coletivas e de inclusão política, que encontra nas instituições participativas condições para vocalização e deliberação de grupos normalmente excluídos dos processos decisórios.

\section{Instituições participativas no Brasil contemporâneo}

Ao longo da redemocratização brasileira, o tecido da sociedade civil expandiuse em associações e movimentos sociais, agregando novos segmentos sociais que foram se organizando a partir de diferentes recortes temáticos. A diversidade de temas foi conformada principalmente em redes de interações informais e compartilhadas por uma diversidade de indivíduos, grupos e/ou organizações potencializados a partir da construção de identidades coletivas, e do engajamento com suas bandeiras, em muitos casos referentes a elementos culturais, como no caso do movimento feminista e de mulheres.

Como consequência do ciclo de mobilização de saída do regime autoritário e das diversas formas de atuação societária, o texto constitucional alargou os direitos sociais e delineou uma nova arquitetura da participação no cenário brasileiro, impulsionada principalmente pela incorporação de novos elementos provenientes da ação política, social e cultural de diversos atores políticos que garantiram a institucionalização da participação social. Muitos canais de participação institucionalizada formaram-se ao longo desse tempo, constituindo um conjunto diversificado de modelos com alcances diferenciados quanto às possibilidades de participação da sociedade.

Como forma de garantir o importante papel político que cabe à sociedade civil, os canais de participação institucionalizados ao longo desse tempo constituíram um conjunto diversificado de desenhos com alcances diferenciados quanto às possibilidades de participação e decisão política. A diversidade de desenhos participativos é ampla, entre os quais: conselhos gestores de políticas, conferências 
temáticas ou conferências de políticas públicas, reuniões com grupos de interesses, planos plurianuais ou orçamentos participativos, ouvidorias, audiências públicas e consultas públicas, além de outros formatos que o governo utiliza para publicizar suas ações e receber demandas e opiniões, como os sítios da internet (PIRES; VAZ, 2012).

Avritzer (2008) afirma que a análise dos tipos de arranjos participativos permite diferenciá-los a partir três importantes variáveis: a iniciativa na proposição do desenho, a organização da sociedade civil e a vontade política do governo em implementar a participação. Detendo-se nos diferentes desenhos institucionais participativos, a partir da literatura recente, Avritzer (2009) identifica pelo menos três desenhos por meio dos quais os cidadãos ou associações da sociedade civil podem participar do processo de tomada de decisão política. O primeiro é o desenho participativo de "baixo para cima", quando há livre entrada de qualquer cidadão no processo participativo e as formas institucionais da participação ocorrem do cidadão para a instituição. Ao caracterizar o desenho de baixo para cima, destaca-se que o processo se inicia com a sociedade civil e diz respeito a instituições com seus interesses definidos de forma coletiva. 0 autor identifica esse desenho institucional de baixo para cima no orçamento participativo.

O segundo desenho, que envolve a "partilha de poder", apresenta-se principalmente nos conselhos de políticas, de direitos ou, ainda, conselhos temáticos. Essa instituição participativa é constituída mediante uma representação e participação simultânea, tanto da sociedade civil, como da sociedade política, com desenho de "partilha de poder", que se diferencia do anterior, entre outros aspectos, por não incorporar um número amplo de atores sociais (AVRITZER, 2008). O terceiro desenho participativo, ainda de acordo com Avritzer (2008), refere-se à "ratificação pública", que é um processo em que os atores da sociedade civil não participam do processo decisório, mas são chamados a referendá-lo publicamente. A grande diferença entre esse formato e os outros dois é que esse não se inicia com a deliberação política.

Considerando os três desenhos participativos mais gerais elencados por Avritzer (2008), considera-se que as conferências podem ser incluídas como um desenho de baixo para cima, pois essas IPs possibilitam livre acesso dos cidadãos nas primeiras etapas e, em seu desenvolvimento, os participantes escolhem seus representantes. $\mathrm{Na}$ articulação entre participação, deliberação e representação, as proposições de diretrizes e intervenções seguem o percurso de baixo para cima, seja pelo fluxo decisório dos cidadãos para as instituições, seja no que se refere às suas etapas nos três níveis de governo e articulação do local ao nacional.

Nesse sentido, cabe referenciar Souza et al. (2013), que buscam caracterizar essas IPs, identificando, a partir da diversidade de arranjos, os casos típicos e atípicos, 
considerando elementos distintos de seu desenho e funcionamento. Em seus casos típicos e a despeito de variações nas fases das conferências, os autores apontam a estrutura escalonada, que pode ser remetida ao desenho mais geral de baixo para cima.

\section{As conferências de políticas públicas no Brasil}

Com a institucionalização de novos espaços de participação nas políticas públicas, impulsionados pelo processo de redemocratização brasileira, houve um realinhamento das conferências nacionais - mecanismo de formulação e orientação de políticas públicas criado, inicialmente, na década de 1930 -, sobretudo mediante a incorporação expressiva da sociedade civil e a ampliação de seus papéis.

Pogrebisnchi e Santos (2010) demonstram que as conferências tornam-se cada vez mais inclusivas pela sua amplitude e abrangência, em consequência da ampliação dos temas envolvidos, contemplando crescentemente direitos das minorias e dos segmentos sociais mobilizados. No âmbito nacional, ocorreu uma ampliação muito expressiva de temas e edições de conferências: entre 1998 e 2009, ocorreram 88 conferências, sendo que 55 dessas foram realizadas no período de 2003-2009. No que se refere à ampliação de temas, isso ocorreu incluindo temas ligados às minorias. Destaca-se que, no Governo Collor, ocorreram conferências sobre dois temas, ampliando-se o número para seis no Governo Itamar; 10 no Governo Fernando Henrique; e 32 no Governo Lula, com 22 novos temas (POGREBISNCHI; SANTOS, 2010). Além disso, as conferências envolvem um conjunto heterogêneo de participantes que representam uma diversidade de grupos sociais. As conferências colocam em pauta as já conhecidas gramáticas da representação, da participação e da deliberação (POGREBISNCHI, 2012), ao permitirem que os cidadãos e cidadãs envolvam-se na formulação, execução e controle de políticas públicas (POGREBISNCHI; SANTOS, 2010).

Nesse contexto, as conferências passam crescentemente a objeto de abordagem em inúmeros trabalhos acadêmicos (PogrebisnCHI; SANTOS, 2010; PogreBISNCHI, 2012; Cunha, 2012; SouzA, 2011, 2012; PIRES; VAZ, 2012; AVRITZER; SouZA, 2013; SouzA et al., 2013).

Souza (2012) destaca que as conferências fortalecem o diálogo entre Estado e sociedade civil e são canais de participação no ciclo de políticas públicas, que dão à sociedade a oportunidade de envolvimento em sua formulação, monitoramento, avaliação e controle. Ao caracterizarem as conferências e observarem sua relativa heterogeneidade, Souza et al. (2013) apontam como objetivos dessas IPs, além da própria participação, a alimentação da agenda governamental, a apresentação de proposições e a avaliação de políticas públicas. 
Brasil e Carneiro (2011) observam a diversidade de desenhos, de características e finalidades das conferências, destacando, para além dos aspectos já referidos de ampliação da participação e inclusão política. Em relação às suas características e desenho, Pires e Vaz (2012) destacam as conferências como eventos que ocorrem com certa periodicidade (geralmente bianual), nos três níveis de governo, determinando as principais questões e direcionamentos normativos de políticas públicas. Souza et al. (2013) indicam, entre outros aspectos típicos, a realização de etapas preparatórias interconectadas, podendo ocorrer, nos diversos momentos, a realização de plenárias, grupos de trabalho, oficinas, palestras.

Nesse sentido, retomando o traço mais geral do desenho institucional - a característica de baixo para cima -, destaca-se que esse traço se evidencia no âmbito intergovernamental: as conferências partem da percepção das demandas locais, ampliando o seu olhar para as demandas estaduais e, posteriormente, para as nacionais, por meio da articulação de diversos segmentos sociais, canalizando a participação ampliada (e territorializada) no âmbito local, para a representação nas etapas estaduais e nacional. Assim, o desenho das conferências tem características ascendentes no que se refere à participação e à inclusão política, como também na forma de articulação intergovernamental. Nesse sentido, as conferências nacionais de políticas públicas constituem um dos mais importantes instrumentos de participação social, que inovam a arquitetura de participação no Brasil.

Por serem geralmente espaços de livre participação, como já mencionado, qualquer pessoa tem o direito de participar das conferências nos momentos iniciais na etapa municipal. De maneira geral, são cinco as categorias representadas nas conferências: usuários, trabalhadores, movimentos sociais, empresários e sindicatos. Além desses, estão mencionados os prestadores de serviços, organizações não governamentais, entidades profissionais, acadêmicas e de pesquisa (TEIXEIRA; SOUZA; LIMA, 2012). Em relação à inclusão política, Cunha (2012) observa que o potencial das conferências relaciona-se com o perfil dos participantes, cabendo verificar se a população tradicionalmente excluída de processos participativos encontra possibilidade de presença e expressão.

Em relação ao poder de intervirem ou influenciarem as decisões relativas às políticas públicas, as conferências podem ser consultivas, deliberativas ou, ainda, podem conjugar ambas as dimensões, dependendo da sua atribuição. Seus papéis, finalidades e atribuições são, geralmente, definidos por lei ou instrumento normativo. Contudo, Cortês (2011) afirma que as conferências interferem na formação da agenda de debates setoriais e favorecem a explicitação de demandas sociais locais, constituindo mecanismos eficazes que canalizam demandas sociais e propiciam a avaliação de serviços públicos, mas nem sempre as deliberações resultam em políticas que de fato são implementadas. 
Assim, as conferências, além de constituírem espaços de participação, inclusão política e fortalecimento do controle público, cumprem um importante papel na elaboração de políticas para as áreas temáticas e setoriais em questão. Conforme apresentado, as conferências possuem como importante prerrogativa a inclusão de grupos marginalizados mediante participação política. Valorizar e reforçar a participação desses grupos em espaços de discussão e debate político é uma forma de promover justiça e reduzir as desigualdades sociais. Nesse sentido, as conferências cumprem um importante papel na construção de estratégias elaboradas pelos próprios sujeitos de direitos em parceria com o governo e outros atores sociais. Essa articulação coletiva favorece a elaboração de políticas mais próximas da realidade local e que têm maior possibilidade de alterar a realidade social. No que se refere às conferências de grupos minoritários, essas podem ser desdobradas em ações e programas para subgrupos, como no caso da conferência nacional de políticas para as mulheres, que delibera diretrizes para as mulheres negras, idosas, com deficiência, lésbicas, entre outras. Assim, as políticas de minorias tendem a ser transversais em seu conteúdo e constituem espaços de deliberação de políticas específicas para determinados grupos minoritários definidos por suas singularidades, mas também de políticas setoriais inclusivas de caráter transversal.

\section{Conferências de políticas públicas para as mulheres em Belo Horizonte}

Foi a partir de 1992, com a eleição de Patrus Ananias para Prefeito de Belo Horizonte pela Frente $\mathrm{BH}$ Popular, que se iniciou na cidade uma proposta de gestão voltada ao resgate dos ideais democráticos, projeto defendido pelo Partido dos Trabalhadores. Foram cinco mandatos consecutivos por partidos de centroesquerda, os quais institucionalizaram um projeto de transformação política na cidade, destinado a promover a justiça social e a participação popular (WAMPLER, 2010). Nesse contexto, nos diversos campos temáticos e setoriais, construíram-se instituições participativas: conselhos, orçamento participativo, arranjos específicos de participação em programas e conferências municipais em casos nos quais não havia ainda conferências nacionais.

A partir do desenho participativo de baixo para cima, os municípios são peçaschave na realização das conferências. No caso específico objeto deste estudo, observa-se que o desenho participativo proposto pela metodologia de organização das conferências de políticas para as mulheres na cidade de Belo Horizonte evidencia a característica do desenho de baixo para cima na primeira etapa, na qual o cidadão tem livre acesso ao processo participativo. Nesse sentido, o caráter de livre acesso na etapa municipal permite a ampliação da participação garantindo maior inclusão política, principalmente de cidadãos e cidadãs de baixa renda e status. 
No Município de Belo Horizonte, para que as conferências de políticas para as mulheres se realizassem, foi necessário (de acordo com os dados dos relatórios de avaliação das CMPM 2004, 2007 e 2010) contar com a participação do Conselho Municipal dos Direitos da Mulher (CMDM), da Coordenadoria Municipal dos Direitos da Mulher (Comdim) e das representantes locais das nove Regionais Administrativas, que organizaram e convocaram as conferências em consonância com as prerrogativas dos regimentos de âmbito nacional, estadual e municipal. De acordo com os dados extraídos desses relatórios (Tabela 1), participaram das três conferências cerca de 4.500 pessoas que debateram e elaboraram 370 propostas aprovadas coletivamente.

Tabela 1: Número de participantes nas conferências de política para as mulheres de Belo Horizonte

\begin{tabular}{c|c|c|c}
\hline & I CMPM (2004) & II CMPM (2007) & III CMPM (2010) \\
\hline & 1500 & 1636 & 1054 \\
\hline Total & 1500 & 1636 & 1054 \\
\hline
\end{tabular}

Fonte: Elaboração própria a partir de Belo Horizonte 2004, 2007, 2010

As conferências municipais de políticas para as mulheres (CMPM) buscam incorporar os cidadãos e cidadãs diretamente na determinação das agendas das políticas em foco. Como característica de seu desenho, a população da cidade pode participar livremente na fase das pré-conferências; entretanto, nas fases seguintes, só poderão participar os delegados eleitos. De acordo com os dados dos relatórios das CMPMs (2004, 2007, 2010), a organização das conferências contou com uma metodologia própria da cidade, já empregada em outras IPs, como o Orçamento Participativo. Na primeira fase da organização, são realizadas pré-conferências, a participação é aberta e o acesso é livre a todos os moradores das Regionais Administrativas. Esse formato busca incentivar a participação e o debate de forma descentralizada.

Nas etapas da pré-conferência e conferência municipal, as atividades são organizadas em três momentos: (i) o trabalho é iniciado com uma palestra normalmente sobre o tema central da conferência; (ii) os participantes debatem nos grupos de trabalho os eixos orientadores da conferência e apresentam as propostas para serem aprovadas; e (iii) as propostas são apresentadas para aprovação na plenária final e os delegados são eleitos para as etapas seguintes. Nessas etapas participam as(os) delegadas(os) eleitas(os) na etapa anterior com representação da sociedade civil e de instituições públicas (Executivo, Legislativo e Judiciário). As(os) delegadas(os) são organizadas(os) em grupos de trabalho com eixos definidos, compostos cada um por uma coordenadora mediadora e uma redatora que será 
responsável pela organização do debate e das propostas aprovadas. Ao término do debate, cada grupo aprova as propostas do eixo, que irão compor o documento final da conferência municipal. Após a eleição das delegadas para etapa estadual, realizase a plenária final. A redatora de cada grupo apresenta as propostas aprovadas e há abertura para destaques para as delegadas com direito à voz e voto presentes. Após a apresentação dos destaques, as propostas são aprovadas por aclamação e a conferência encerrada com a apresentação das delegadas eleitas para a etapa estadual.

Posteriormente à realização da conferência, a comissão organizadora elabora o documento final e procede aos encaminhamentos legais, ficando sob a responsabilidade da Comdim encaminhar as deliberações aprovadas para as devidas áreas de políticas municipais evidenciadas. Nesse contexto, o CMDM assume o papel de controle social e passa a ser o responsável pelo acompanhamento das ações de governo, garantindo que as propostas sejam assumidas enquanto política pública no município.

A Tabela 2 buscou sistematizar a apresentação das propostas aprovadas a partir dos eixos orientadores em consonância com o ano da conferência. Observa-se que a conferência de 2004 apresentou um quantitativo maior de eixos e propostas aprovadas, diversificando o debate em torno de vários temas presentes na realidade das mulheres. A partir de 2007 e 2010, as diretrizes se aproximam; todavia, a regra relativa à quantidade de propostas aprovadas mudou, dificultando traçar um comparativo direto entre as duas edições. Entretanto, é interessante observar que o tema relativo à saúde da mulher, direitos sexuais e reprodutivos teve o maior quantitativo de propostas aprovadas no somatório das três edições, reafirmando a importância desse tema para as mulheres. Em seguida, temos a autonomia econômica, a violência contra a mulher e a educação inclusiva e não sexista, que incorpora o tema da diversidade sexual.

\section{Inclusão e políticas públicas a partir das conferência de políticas para as mulheres em Belo Horizonte: a visão das conselheiras do CMDM}

Como mencionado, este trabalho teórico-empírico buscou analisar características do desenho institucional participativo das conferências em foco. Além disso, a partir de pesquisa realizada no período 2012-2013 (REIS, 2013), analisa as conferências de políticas para as mulheres de Belo Horizonte na perspectiva das conselheiras municipais do CMDM, abordando os encaminhamentos e desdobramentos desse processo democrático participativo: obteve-se avanço, favoreceu em alguma medida a inclusão política e a elaboração de políticas a partir das propostas aprovadas. 
Tabela 2: Relação entre eixo orientador, edição e propostas aprovadas nas conferências

\begin{tabular}{|c|c|c|c|c|}
\hline Eixo Orientador & 2004 & 2007 & 2010 & TOTAL \\
\hline Inclusão Social & 11 & & & 11 \\
\hline Segurança Alimentar & 6 & & & 6 \\
\hline Programas, ações e estruturas institucionais & 37 & & & 37 \\
\hline Movimentos sociais: autonomia e organização & 10 & & & 10 \\
\hline Diversidade das mulheres & 19 & & & 19 \\
\hline Trabalho e empregabilidade & 20 & \multirow{4}{*}{29} & & \multirow{4}{*}{75} \\
\hline Geração de renda e economia solidária & 19 & & & \\
\hline Autonomia no mundo do trabalho e cidadania & & & & \\
\hline $\begin{array}{l}\text { Autonomia econômica e igualdade no mundo } \\
\text { do trabalho, com inclusão social }\end{array}$ & & & 7 & \\
\hline $\begin{array}{l}\text { Educação não sexista, antirracista e não } \\
\text { discriminatória }\end{array}$ & 23 & \multirow{3}{*}{18} & & \multirow{3}{*}{44} \\
\hline Educação inclusiva e não sexista & & & & \\
\hline $\begin{array}{l}\text { Educação inclusiva, não sexista, não racista, } \\
\text { não homofóbica e não lesbofóbica }\end{array}$ & & & 3 & \\
\hline Violência contra a mulher & 13 & \multirow{3}{*}{10} & & \multirow{3}{*}{19} \\
\hline Enfrentamento da violência contra as mulheres & & & & \\
\hline $\begin{array}{l}\text { Enfrentamento de todas as formas de violência } \\
\text { contra as mulheres }\end{array}$ & & & 6 & \\
\hline $\begin{array}{l}\text { Saúde das mulheres e direitos sexuais e } \\
\text { direitos reprodutivos }\end{array}$ & 35 & 71 & 8 & 114 \\
\hline Mulher e poder & 9 & \multirow{3}{*}{11} & & \multirow{3}{*}{14} \\
\hline Reforma Política & & & & \\
\hline $\begin{array}{l}\text { Participação das mulheres no espaço de poder } \\
\text { e decisão }\end{array}$ & & & 5 & \\
\hline Propostas aprovadas & 202 & 139 & 29 & 370 \\
\hline
\end{tabular}

Fonte: Elaboração própria a partir de Belo Horizonte, 2004, 2007, 2010.

Ao perguntar às conselheiras se as mesmas consideram que as conferências municipais incentivam a participação das mulheres, verificou-se que sete acreditam que sim e três, não; entretanto, surgiram algumas considerações importantes sobre o aspecto da participação das mulheres em conferências municipais apresentadas pelas participantes:

Mas fica muito aquém, só participam os movimentos sociais, a política fica muito restrita a esse grupo, a demanda é muito pouco acionada (representante do governo). 
Vão muitas pessoas para disputar a indicação para outras fases e os debates ficam no vazio (representante da sociedade civil).

As mulheres estão mais conscientes das suas possibilidades e sobre o que existe de políticas públicas para as mulheres (representante da sociedade civil).

Das mesmas participantes, né! Acho que as pré-conferências possuem chances de promover maior inclusão política de outras mulheres; penso que talvez fosse melhor reforçar a participação nessa esfera (representante da sociedade civil).

São praticamente as mesmas pessoas que participam (representante do governo).

Vejo pouca renovação da participação (representante do governo).

As mulheres agora estão bem interessadas em saber os seus direitos, é importante assegurar direitos (representante da sociedade civil).

A conferência é o momento de mobilizar as mulheres para discutir temas a partir de princípios democráticos e que trazem questões importantes como o papel do Conselho da Mulher (representante do governo).

É interessante observar que as representantes governamentais e da sociedade civil demonstram certo ceticismo quanto à possibilidade de ampliação da participação das mulheres. A compreensão dos dois grupos reforça o caráter pouco renovador da participação. A impressão é de que, na primeira fase (pré-conferência), existe a possibilidade de incluir politicamente mais pessoas, o mesmo não ocorrendo na fase seguinte.

Na compreensão de sete conselheiras, as conferências municipais são instituições participativas que ampliam a inclusão política das mulheres. Apenas três consideram que tais instâncias não alcançam tal objetivo, pois, conforme as mesmas:

Deveria ser, mas na prática não funciona com o objetivo de atingir esse fim; em BH não tem movimento organizado que atue diretamente nos espaços participativos (representante da sociedade civil).

O fato de ser o mesmo público que participa não atinge este objetivo (representante do governo).

Entretanto, as que consideram que as conferências ampliam a inclusão política das mulheres apontam que:

A participação amplia a visão das mulheres, que passam a conhecer as políticas públicas e como são implementadas, dessa forma acionam os órgãos exigindo o direito. $\mathrm{O}$ movimento social só exige a garantia de direitos quando bem organizado (representante da sociedade civil). 
É um espaço que permite se posicionar, colocar as ideias, falar em público e empoderar; uma mulher que participa de uma conferência nunca mais é a mesma (representante da sociedade civil).

As mulheres despertam mais para o que está acontecendo, principalmente a partir do encontro com outras mulheres (representante da sociedade civil).

É um dos poucos conselhos que promovem essa inclusão, pois traz as mulheres para esse espaço (representante da sociedade civil).

As informações e debates ampliam o conhecimento (representante do governo).

Um aspecto interessante apontado por nove das entrevistadas é o de que as conferências municipais também têm como função ampliar o conhecimento e a informação das participantes. Algumas complementaram tal constatação com as seguintes afirmativas:

A organização das conferências permite que as participantes façam intervenções na hora certa via moção (representante da sociedade civil).

Gênero e raça têm mais atrito, o movimento negro chega e toma o lugar, esse movimento é um gueto (representante da sociedade civil).

As pessoas ficam nos grupos aguardando apenas a eleição das delegadas, as propostas não são discutidas ou debatidas pelas participantes (representante do governo).

Conforme observado anteriormente, na compreensão da maioria das conselheiras, a participação em conferência possibilita a inclusão política das mulheres a partir do caráter educativo e de transferência de conhecimentos e informações. Outro aspecto presente nessa IP e que se apresenta como muito importante para a inclusão política das mulheres é a possibilidade de participação direta na articulação, interlocução e debate.

Em relação à implementação das decisões aprovadas pelas conferências, somente quatro conselheiras acreditam que as propostas aprovadas são implementadas. Para elas:

As conferências são referências para as políticas públicas (representante do governo).

Fazem parte dessa participação as decisões, a conferência abre espaço para muitas pessoas da base participarem (representante da sociedade civil).

Existem muitas ações que são organizadas a partir das conferências municipais (representante do governo).

Só em relação a algumas ações pontuais (representante do governo). 
Entretanto, alguns questionamentos surgiram e devem ser observados pelo Conselho Municipal dos Direitos da Mulher, pois envolvem tanto as responsabilidades do conselho quanto da gestão pública municipal:

Falta uma instância que seja responsável pela deliberação. Quem faz isto? O conselho faz? (representante do governo)

Mas ao longo do tempo tem que questionar, pois o poder público desfaz, tem que acompanhar para acontecer (representante do governo).

Barra na politicagem dos políticos, tem que brigar muito com os homens (representante da sociedade civil).

A pesquisa demonstra que existe uma dificuldade na articulação e gestão das propostas aprovadas, após a realização das conferências. Essa percepção ocorre porque não há uma compreensão de como os procedimentos são realizados. O que parece é que não existem gestão e acompanhamento das propostas aprovadas. Em relação à instituição participativa das conferências municipais, nota-se que, conforme as conselheiras municipais, esse é um importante espaço participativo de articulação, poder e decisão.

\section{Considerações finais}

A participação social pode afetar diretamente as políticas ao definir novos padrões para os processos de decisão, assim como pode propiciar que a democracia se aprofunde e amplie em sociedades complexas, desiguais e plurais, ou, ainda, que se fortaleçam os sujeitos coletivos envolvidos. Nesse sentido, é fundamental o papel da sociedade civil organizada e do ativismo político que se concretiza nas diversas formas de organização, mobilização e ação coletiva, tais como: movimentos sociais, redes articuladoras, sindicatos ou, ainda, partidos políticos, entre outras. Paralelamente, destaca-se a relevância das instituições participativas que possibilitam o encontro entre sociedade civil e governo, garantindo um novo formato institucionalizado do exercício democrático a partir da inclusão de novos atores que passam a interferir diretamente nas decisões políticas.

No Brasil contemporâneo, ampliou-se expressivamente a infraestrutura participativa, com um grande numero e diversidade de IPs, dentre as quais se destacam as conferências. A partir deste estudo, alguns aspectos relevantes apresentaram-se nas interfaces entre participação social e elaboração de políticas públicas. Uma questão central é garantir que essas instituições participativas e os atores envolvidos se articulem de tal forma que as decisões coletivas sejam absorvidas e implementadas. 
Entre os grupos politicamente minoritários, encontram-se as mulheres que, a partir do movimento feminista, têm a defesa de seus interesses numa perspectiva de gênero e questionamento dos sistemas culturais e políticos construídos em função dos papéis sociais atribuídos historicamente às mulheres. Assim, o movimento feminista implicou avanços referentes à democratização das relações de gênero no âmbito da sociedade, como também nas formas de intervenção do Estado a partir de políticas públicas direcionadas a esse público. Muitas dessas conquistas foram garantidas pela participação nas conferências de políticas para as mulheres realizadas no Brasil a partir de 2004.

Conforme indicado, para as conselheiras municipais da mulher, a participação amplia a visão das mulheres, que passam a conhecer as políticas públicas e como são implementadas, de forma que podem exercer o controle social, acionando os órgãos e exigindo o cumprimento de direitos.

$\mathrm{Na}$ perspectiva da participação das mulheres nas conferências em foco, dois importantes aspectos foram apresentados pelas conselheiras do CMDM. Primeiramente, foi apontado na pesquisa que é a partir das conferências que as mulheres despertam para as suas realidades, principalmente no encontro com outras mulheres. Nesse sentido, a participação não é resultado de processos individuais e sim de processos coletivos (e deliberativos) que se afirmam enquanto importante instrumento de transformação social. Em segundo lugar, no aspecto referente à elaboração de políticas públicas a partir das conferências municipais, a maioria das conselheiras acredita que as propostas aprovadas não foram incorporadas à gestão de políticas públicas para as mulheres na cidade. Na compreensão das conselheiras, existe uma dificuldade na articulação e gestão das propostas aprovadas, após a realização das conferências. Na avaliação desse aspecto, é necessário aprofundar a investigação, analisando todas as políticas públicas elaboradas por cada temática no período pós CMPM.

Outra questão que chama atenção na pesquisa, que merece um estudo mais aprofundado e se relaciona com o que Fung (2004) apresenta, refere-se ao aspecto central da democracia participativa, ou seja, a igualdade de participação direta das(os) cidadãs(ãos) nos processos de decisão. O discurso correspondente ao movimento das mulheres negras, identificado na pesquisa, aponta a necessidade de repensar a condução dos direitos legítimos dos diversos segmentos presentes no interior do movimento de mulheres. Existem aspectos da luta que podem ser tratados de forma ampla, outros devem atender às especificidades de cada segmento. Esse reconhecimento por parte de todas as participantes é essencial para o fortalecimento da luta que defende a igualdade de gênero, mesmo compreendendo que essa situação não é uma tarefa fácil, posto que a agenda política é limitada para tantas demandas apresentadas. 
De um lado, este estudo pode afirmar, a partir do olhar das conselheiras do CMDM, que as CMPMs permitem a inclusão política de mulheres que participam desse processo de decisão coletiva; por outro, as propostas aprovadas não têm sido utilizadas como referência para elaboração de políticas públicas para as mulheres no município.

Finalmente, as questões apresentadas por esta investigação mostram-se relevantes para o estudo sobre participação social, instituições participativas e conferências de políticas, assinalando-se que esta pesquisa adicionou algumas questões que merecem desenvolvimentos posteriores. É certo que existem limites teóricos e empíricos na pesquisa realizada, mas seus resultados apresentam olhares e indagações em relação às conferências e à elaboração de políticas públicas a partir de suas decisões coletivas que denotam potenciais e avanços indiscutíveis, mas que podem esbarrar em aspectos políticos e institucionais que limitam o alcance das conferências de políticas.

\section{Referências bibliográficas}

AVRITZER, L. Instituições participativas e desenho institucional: algumas considerações sobre a variação da participação no Brasil democrático. Revista Opinião Pública, v. 14, no 1, p. 43-64, 2008.

Editora, 2009.

(org.). Experiências nacionais de participação social. São Paulo: Cortez

Sociedade civil e participação no Brasil democrático. In:

Experiências nacionais de participação social. São Paulo: Cortez Editora, 2009. p. 27-54.

(org.). A dinâmica da participação local no Brasil. São Paulo: Cortez Editora, 2010. Ipea.

AVRITZER, Leonardo; SouZA, Clóvis H.L.S. Conferências nacionais: atores, dinâmicas participativas e efetividade. Brasília: Ipea, 2013.

Belo Horizonte. Prefeitura Municipal de Belo Horizonte. Secretaria Municipal Adjunta de Direitos de Cidadania. Coordenadoria Municipal dos Direitos da Mulher. Relatório Final da I Conferência Municipal de Políticas para as Mulheres. 2004. Material não publicado.

Relatório Final da II Conferência Municipal de Políticas para as Mulheres. 2007. Material não publicado.

Relatório Final da III Conferência Municipal de Políticas para as Mulheres. 2010. Material não publicado.

Belo Horizonte. Prefeitura Municipal de Belo Horizonte. Conselho Municipal dos Direitos da Mulher. Disponível em: <htpp://www.portalpbh.gov.br/pbh>, Acessado em: 12 de novembro 2012.

BENHABIB, S. Rumo a um modelo deliberativo de legitimidade democrática. In: MARQUES, A.C.S. (org.). A deliberação pública e suas dimensões sociais, políticas e comunicativas. (p.109-142.). Belo Horizonte: Autêntica, 2009. p. 109-142. 
BOHAMN, J. O que é a deliberação pública? Uma abordagem dialógica. In: MARQUES, A.C.S. (org.). A deliberação pública e suas dimensões sociais, políticas e comunicativas. Belo Horizonte: Autêntica, 2009. p. 31-84.

BRASIL. Constituição Federal, 1988. Brasília: Senado Federal, 2002.

BRASIL. Presidência da República. Secretaria de Políticas para as Mulheres. I Plano Nacional de Políticas para as Mulheres. Brasília, 2004.

II Plano Nacional de Políticas para as Mulheres. Brasília, 2008.

Disponível em: <http:www.spm.gov.br> Acessado em: 10 de dezembro

de 2012.

BRASIL, F. P. D. Democracia e participação social: a construção de avanços democratizantes nas políticas nacionais pós-1980. 2011. Tese de Doutorado em Sociologia apresentada na Faculdade de Filosofia e Ciências Humanas da Universidade Federal de Minas Gerais. Belo Horizonte.

BRAsIL, F. P. D.; CARNEIRO, R. Democracia y Disenos Institucionales Participativos. Iconos. Revista de Ciências Sociais, v. 15, no 02, p. 71-87, 2011.

Chambers, S. A teoria democrática deliberativa. In: MARques, A.C.S. (org.). A deliberação pública e suas dimensões sociais, políticas e comunicativas. Belo Horizonte: Autêntica, 2009. p. 239-267.

COHEN, J. Deliberação e legitimidade democrática. In: MARQuES, A.C.S. (org.). A deliberação pública e suas dimensões sociais, políticas e comunicativas. Belo Horizonte: Autêntica, 2009. p. 85-108.

CORTES, S. V. As diferentes instituições participativas existentes nos municípios brasileiros. In: PIRES, R.C. (org.). Efetividade das instituições participativas no Brasil: estratégias de avaliação. Brasília: Ipea, 2011. v. 7, p. 137-150.

CUNHA, E. S. M. Conferências de políticas públicas e inclusão participativa. (Texto para discussão no 1733). Rio de Janeiro: Ipea, maio 2012.

FARIA, C.F. Democracia deliberativa: Habermas, Cohen e Bothman. Revista Lua Nova, no 49, p. 47-67, 2000.

O que há de radical na teoria democrática contemporânea: anais do debate entre ativistas e deliberativos. Revista Brasileira de Ciências Sociais, v. 25, p. 101-111, 2010.

FUNG, A. Receitas para esferas públicas: oito desenhos institucionais e suas consequências. In: CoELHO, V. S. et al. Participação e deliberação: teoria democrática e experiências institucionais no Brasil. São Paulo: Editora 34, 2004. p. 173-209.

HELD, D. Modelos de democracia. Belo Horizonte: Editora Paidéia, 1987.

Moronı, José Antônio. O direito à participação no Governo Lula. In: AVRITZER, L. Experiências nacionais de participação social. São Paulo: Cortez, 2009.

PATEMAN, C. Participação e teoria democrática. Rio de Janeiro: Paz e Terra, 1970.

PIRES, R.R. C.; VAZ, A. Participação social como método de governo? Um mapeamento das "interfaces socioestatais" nos programas federais. (Texto para discussão $\mathrm{n}$ ㅇ 1707). Rio de Janeiro: Ipea, 2012. 
PogREBINSHI, T. Conferências nacionais de políticas públicas para grupos minoritários. (Texto para discussão no 1741). Rio de Janeiro: Ipea, Junho 2012.

POgReBinSHI, T; SANTOS, F. Participação como representação: o impacto das conferências nacionais de políticas públicas no Congresso Nacional. DADOS - Revista de Ciências Sociais, Rio de Janeiro, v. 54, no 3, p. 259-305, 2011.

REIS, G. G. Avanços e desafios da institucionalização da democracia participativa em Belo Horizonte a partir das conferências municipais de políticas para as mulheres realizadas no período de 2004 a 2010. 2013. Dissertação de Mestrado apresentada no Mestrado em Administração Pública da Escola de Governo da Fundação João Pinheiro. Belo Horizonte.

SouzA, C.H.L. A que vieram as conferências nacionais? Uma Análise dos objetivos dos processos realizados entre 2003 e 2010. (Texto para discussão no 1718) Rio de Janeiro: Ipea, março 2012.

Conferências e os desafios metodológicos de seu estudo. In: PIRES, Roberto Rocha C. (org.) Efetividade das instituições participativas no Brasil: estratégias de avaliação. Brasília: Ipea. p. 197-210.

et al. (2013) Conferências típicas e atípicas: um esforço de caracterização do fenômeno político. In. AVRITZER, Leonardo; SouzA, Clóvis H.L.S. Conferências nacionais: atores, dinâmicas participativas e efetividade. Brasília: Ipea, 2013.

TEIXEIRA, A.C.C. et al. Arquitetura da participação no Brasil: uma leitura das representações políticas em espaços participativos nacionais. (Texto para discussão no 1735). Rio de Janeiro: Ipea, maio 2012.

WAMPLER, B. Transformando o Estado e a sociedade civil por meio da expansão das comunidades política, associativa e de políticas públicas. In: AVRITZER, L. (org.). A Dinâmica da participação local no Brasil. (São Paulo: Cortez Editora, 2010. p. 394-439.

Flávia de Paula Duque Brasil

Mestre e Doutora em Sociologia pela Universidade Federal de Minas Gerais (UFMG), Professora da Escola de Governo/Fundação João Pinheiro, Bolsista de Incentivo à Pesquisa da Fapemig. Contato: flavia.brasil@fjp.mg.gov.br

Mestre em Administração Pública, pela Fundação João Pinheiro (FJP) e Consultora do Projeto Objetivos de Desenvolvimento do Milênio Brasil (PNUD). Contato: girlene.reis@hotmail.com 


$$
\text { RSP }
$$

